\title{
Monitoring Susceptibility Status of Phlebotomus argentipes (Diptera: Psychodidae) at Bihar (India) for the Procurement of Homozygous DDT Resistant Colony
}

\author{
Aarti Rama ${ }^{1}$, Vijay Kumar ${ }^{1 *}$, Shreekant Kesari', Vijay Pratap Singh ${ }^{1}$ and Pradeep Das ${ }^{2}$
}

${ }^{1}$ Department of Vector Biology and Control, Rajendra Memorial Research Institute of Medical Sciences (Indian Council of Medical Research), Agamkuan, Patna - 800 007, Bihar, India

${ }^{2}$ Rajendra Memorial Research Institute of Medical Sciences (Indian Council of Medical Research), Agamkuan, Patna - 800 007, Bihar, India

\begin{abstract}
Brisk and continuous application of routine insecticide i.e., dichlorodiphenyltrichloroethane (DDT) for long had evoked the problem of resistance among Indian Visceral Leishmaniasis (VL) vector Phlebotomus argentipes (Diptera: Psychodidae) in Bihar, affecting DDT based strategies for controlling vector population. In this way, strong resistant colony of $P$. argentipes would provide fundamental platform to reveal the mechanistic reason behind the arousal of DDT resistance among sand flies. Present report summarizes our experiences with baseline establishment and maintenance of DDT resistant colony of $P$. argentipes after studying susceptibility profile for districts of Bihar. The district with lowest susceptibility or highest resistance against DDT would inculcate the collection of resistant sand flies for procuring resistant colony of $P$. argentipes, the foremost objective of the present study. For this, DDT susceptibility test were carried out at seven districts of Bihar (India), followed by the selection of Vaishali district as a 'perfect site for resistant sand fly collection'. Here Percentage Mortality Range (PMR) and Corrected Mortality Rate (CMR) i.e., 41.00-52.73 and $44.83 \%$ respectively were recorded to be lowest indicating the presence of sand flies highly resistant to DDT. Single blood-fed female and a male P. argentipes, collected from the selected site were confined together for oviposition and rearing of developmental stages for obtaining its next generation.. Inherited DDT resistant character of progenies of highly resistant parent was estimated and compared by quantifying Mortality Frequency Rate and DDT Resistant Rate through the insecticide susceptibility test conducted at its subsequent generations. Significant fluctuation within DRR (with $67.29 \pm 17.28 ; 95 \%$ C.I=54.49-80.09) observed throughout the $7^{\text {th }}$ generation established intrusion of susceptibility factor in homozygous resistant colony after achieving absolute resistant in $\mathrm{F} 4$ generation of $P$. argentipes. Though invaded with insecticide susceptibility, resistance dominate the colony. So far, colony has reached its $7^{\text {th }}$ generation and culturing well in the laboratory.
\end{abstract}

Keywords: Dichlorodiphenyltrichloroethane (DDT); Visceral Leishmaniasis (VL); Phlebotomus argentipes; DDT resistant colony; DDT susceptibility test

\section{Introduction}

Though insecticides are very much helpful in controlling and checking out the nuisance of noxious vectors belonging to phylum arthropoda and class insecta [1,2], intrusion and prevalence of insecticide resistance has acquired world-wide importance since the discovery of resistance towards dichlorodiphenyltrichloroethane (DDT) - an insecticide of choice, firstly reported in case of houseflies [3]. Insects having a short life cycle and high rates of reproduction are likely to develop resistance more rapidly than those species possessing lower rate of reproduction, as any resistant gene can rapidly spread throughout the population [4]. In the field of applied entomology, the term "Resistance" often refers to the natural characteristics of a species [5]. According to the report of Insecticide Resistance Action Committee (IRAC), "Resistance is the selection of a heritable characteristic in an insect population that results in the repeated failure of an insecticide product to provide the intended level of control when used as recommended" [4]. Presently, resistance has been widely used to describe strains, within species, that are abnormally less susceptible to insecticides than the original or natural population of the species. Such strains arise after selective mortality followed by extensive use of insecticide for controlling insect population [5] ultimately leading to serious impediment to successful integrated pest management. Historically, in India Phlebotomine sand flies were supposed to be highly susceptible to all type of insecticides; but continuous and indiscriminate use of routine insecticides imposed a problem of vector resistance followed by the failure of its efficacy. Various reports on VL vector resistance at Bihar produces testimony to this assertion, where spraying with DDT has continued since 1976 [6-8]. Resistance to DDT in Phlebotomus argentipes, a proven vector of Kala- azar in India, was reported for the first time from the village of Samastipur district [9]. Since then, lots of investigatory work with biochemical as well as genetical aspect of resistance mechanism of $P$. argentipes, as reported in case of Phlebotomus papatasi [10] are awaited due to the lack of strong resistant colony of $P$. argentipes, which is supposed to be very tedious and challenging task in itself. Though being, a tedious task, our laboratory has successfully colonized mixed strain of $P$. argentipes comprising more than five hundred generations of resistant as well as susceptible sand flies that had never been exposed to any insecticide, since 1990s. In a way to prepare a homozygous DDT resistant strain of $P$. argentipes in the controlled condition, various preliminary approaches were adopted. Present communication emphasized on

*Corresponding author: Dr. Vijay Kumar, Assistant Director, Head of Department, Department of Vector Biology and Control, Rajendra Memorial Research Institute of Medical Sciences (ICMR), Agamkuan, Patna- 800 007, Bihar, India, Tel: 091 0612-2636651; Fax: 091-0612-2634379; E-mail- vijayrnagar@hotmail.com Received July 15, 2015, 2015; Accepted August 10, 2015; Published August 17, 2015

Citation: Rama A, Kumar V, Kesari S, Singh VP, Das P (2015) Monitoring Susceptibility Status of Phlebotomus argentipes (Diptera: Psychodidae) at Bihar (India) for the Procurement of Homozygous DDT Resistant Colony. J Trop Dis 3 : 170. doi:10.4172/2329891X.1000170

Copyright: (c) 2015 Rama A, et al. This is an open-access article distributed under the terms of the Creative Commons Attribution License, which permits unrestricted use, distribution, and reproduction in any medium, provided the original author and source are credited. 
laboratory experiences with baseline establishment and maintenance of resistant colony of $P$. argentipes (Diptera: Psychodidae) towards routine insecticide i.e., DDT after understanding the susceptibility status of districts lying under the province of Bihar. In this regard, a wellestablished DDT resistant colony of $P$. argentipes comprising maximum percentage of resistant insect towards the DDT will facilitate revealing unsolved secrets behind resistance mechanism on "bio-chemicogenetical" ground as well as validation of cross-resistance among sand flies towards various insecticides for exploring and monitoring new strategies regarding vector control.

\section{Materials and Methods}

In a way of initiating the homozygous resistant colony of Phlebotomus argentipes - the vector of Indian Visceral Leishmaniasis (VL), comprising maximum percentage of sand flies that are resistant towards dichlorodiphenyltrichloroethane (DDT), following strategies were adopted.

\section{Site selection for susceptibility test}

Previous reports establish that districts lying at the northern side of Ganges course, in Bihar are highly endemic region for VL [1114]. Here, despite of adopting every technique for controlling the menace caused by vector population, resurgence of sand flies had been continuously reported followed by arousal of resistance among the sand flies $[15,16,11,12]$. Hence for the present study, seven districts lying at the northern side of Ganges course in Bihar state namely Daulatpur chandi village of Vaishali district $\left(25.6833^{\circ} \mathrm{N}, 85.2167^{\circ} \mathrm{E}\right)$, Bocha of Muzaffarpur district $\left(26.1200^{\circ} \mathrm{N}, 85.4000^{\circ} \mathrm{E}\right)$, Patori of Samastipur $\left(25^{\circ} 51^{\prime} \mathrm{N}, 85^{\circ} 47^{\prime} \mathrm{E}\right)$, Ekma of Saran district $\left(25.9167^{\circ} \mathrm{N}, 84.7500^{\circ} \mathrm{E}\right)$, Maheshi of Saharsa district ( $\left.25^{\circ} 53^{\prime} 0^{\prime \prime} \mathrm{N}, 86^{\circ} 36^{\prime} 0^{\prime \prime} \mathrm{E}\right)$, Barauli of Gopalganj district $\left(26.4700^{\circ} \mathrm{N}, 84.4300^{\circ} \mathrm{E}\right)$ and Baliya of Begusarai district $\left(25^{\circ} 25^{\prime} \mathrm{N}, 86^{\circ} 8^{\prime} \mathrm{E}\right)$ were shortlisted for conducting susceptibility test for better understanding the susceptibility status of each selected districts falling under the province of Bihar. The generated data would help better in selecting site to be treated as 'perfect site for resistant sand fly collection' for establishment of homozygous DDT resistant strain of P. argentipes.

\section{Susceptibility test for $P$. argentipes of each study sites}

DDT susceptibility test for P. argentipes, collected from each study site, were carried out according to the recommended protocol of World Health Organisation (WHO) [17,18] for determining susceptibility, during the peak seasons i.e., in April- August month of year 2011-2013. For this, $P$. argentipes were collected from cattle sheds, human dwellings and mixed dwellings of each study site during 0600-0800 hrs, with the help of mouth aspirator and hand operated flashlight. The captured sand flies were collected in glass test tubes (labelled with the site of collection), provided with $10 \%$ sucrose solution soaked cotton plug and transported to the laboratory of Rajendra Memorial Research Institute of Medical Sciences (ICMR), Agamkuan, Patna. Batches of 10-15, bloodfed female as well as male $P$. argentipes, were carefully released into the separate green dot-marked holding tubes of insecticide susceptibility testing kit specified by World Health Organisation (WHO), with the help of mouth aspirator. All the $P$. argentipes confined in the holding tubes for an hour for acclimatization with new environment of testing kit were then transferred into the red dot-marked exposure tubes lined with $4.0 \%$ DDT impregnated paper (specified by WHO), through the filling hole in the sliding unit of susceptibility testing kit. The exposure tubes were kept in upright position for an hour. After an hour, the insecticide-exposed sand flies were transferred to the holding tubes lined with filter paper for recovery purpose and supplemented with $10 \%$ glucose solution soaked cotton pad at the top of screen. The holding tubes were kept in upright position for 24 hours under the diffused light. The complete methodology for determining susceptibility/resistance of sand flies to DDT is illustrated in Figure 1. During the recovery period, temperature and relative humidity were maintained at $28 \pm 2^{\circ} \mathrm{C}$ and 80 $\pm 5 \%$ respectively. The final mortality count after 24 hours of insecticide exposure were recorded and adjusted according to the undernoted Abbot's formula for obtaining corrected mortality $[17,18]$.

Corrected Mortality $(\mathrm{CM})=[(\%$ test mortality- $\%$ control mortality $) \times 100]$

[100- \% control mortality]

The results interpreted in accordance with WHO recommendations for malaria vectors $(18)$ as well as sand flies $[18,19]$, where CM lying between $98-100 \%$ indicated susceptible, $80-97 \%$ CM regarded as tolerance, while $<80 \% \mathrm{CM}$ suggested strong indicator for resistant strain $[17,18]$. The results of $0.4 \%$ DDT susceptibility tests for each study sites were conducted in 2-3 replicates for the assurance of results (Table 1).

\section{Collection and colonization of DDT resistant sand flies}

After site selection, process of sand fly collection from the region estimated with highest level of DDT resistant served as an important criterion for establishment of strong DDT resistant colony of $P$. argentipes. For this, diurnal resting wild, adult sand flies of both sexes were captured during 0600-0800 hrs with the help of mouth aspirator and hand operated flashlight from the places of human dwelling and cattle sheds at Vaishali district of Bihar state, during the peak months from April 2014-August 2014. The collected sand flies were gently confined to the plaster-lined Hilton pots, wrapped in moistened cloth and were carefully transported to the Rajendra Memorial Research Institute of Medical Sciences (ICMR), Agamkuan, Patna. The physical shock and jerks to insects were avoided during transportation. The captured sand flies were released into the wooden-framed, wiremeshed, cloth-lined barraud cage $(42 \times 36 \times 36 \mathrm{~cm})$ for their adjustment to the new environment of insectary of Vector Biology and Control Division, Rajendra Memorial Research Institute of Medical Sciences (ICMR), Agamkuan, Patna, after which the Phlebotomus argentipes (Diptera: Psychodidae) were sorted out with the help of provided identification key [20]. Only healthy and strong individuals were retained for colonizing purpose after offering blood meal to female $P$. argentipes [21-23]. Briefly, the sand flies were transferred to the clean and dried wooden-framed, wire-meshed, cloth-lined and glassscreened feeding cage $(132 \times 36 \times 36 \mathrm{~cm})$. Along with that, two healthy rabbits (4-6 week old) with hairless back, were obtained from the Animal House of Rajendra Memorial Research Institute of Medical Sciences (ICMR), Agamkuan, Patna, were anesthetized and introduced into the same cage with sand flies for 2-3 hours. During the blood feeding session, the glass-screen of cage was covered with cotton cloth, for providing warmth and darkness to feeding insects. This enhances the blood feeding percentage. On completion of feeding process, single blood-engorged female along with a male sand fly as a parent generation for forthcoming filial generations (F-generations) were selected and confined in each 20 plaster-lined Hilton pots $(7 \times 7 \mathrm{~cm})$ with meshed lid, purposely made for oviposition by female sand flies [22]. The female sand flies were allowed to oviposit on the plastered surface of Hilton pots that were kept on damp cloth for providing uninterrupted supply of relative humidity $80 \pm 5 \%$ under the controlled condition of insectorium maintained at temperature $28 \pm 2^{\circ} \mathrm{C} ; 12 \mathrm{hrs}$ (L:D). The pots were examined daily for egg-deposition. Subsequently, 
Citation: Rama A, Kumar V, Kesari S, Singh VP, Das P (2015) Monitoring Susceptibility Status of Phlebotomus argentipes (Diptera: Psychodidae) at Bihar (India) for the Procurement of Homozygous DDT Resistant Colony. J Trop Dis 3: 170. doi:10.4172/2329891X.1000170

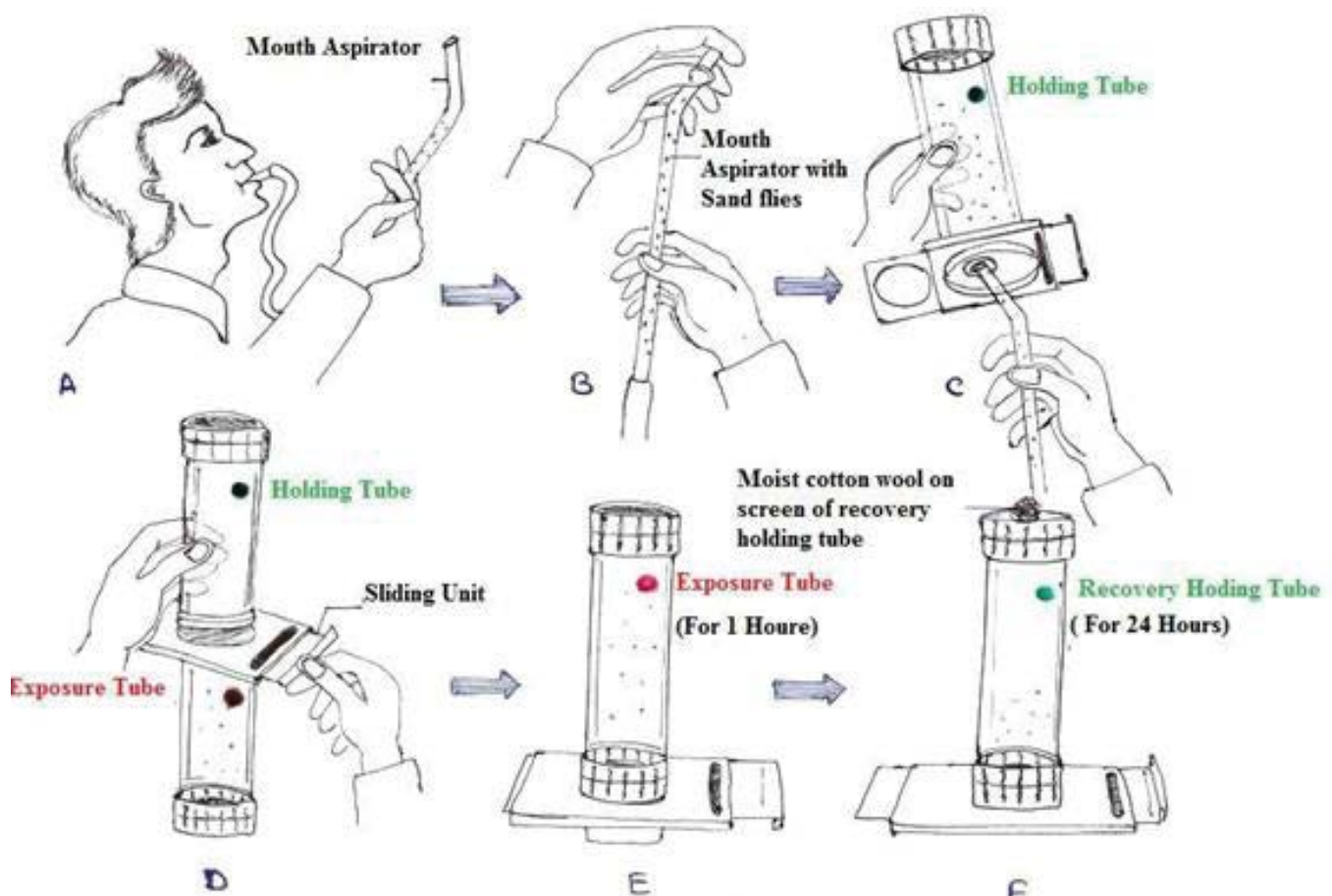
A- Capturing sand flies with Mouth Aspirator
B- Mouth Aspirator with Sand flies
C- Releasing sand flies to the Holding Tube
D-Transferring sand flies to the Exposure Tube
E- Exposure of sand flies to Insecticide, i.e., DDT
F- Sand flies in the Holding Tube for recovery from DDT exposure effect.

Figure 1: Pictorial representation of complete methodology for determining the Susceptibility/ Resistance of P. argentipes towards DDT as prescribed by WHO.

\begin{tabular}{|c|c|c|c|c|c|c|c|}
\hline \multirow[b]{2}{*}{$\begin{array}{l}\text { Susceptibility test } \\
\text { conducted for sand } \\
\text { flies of study sites }\end{array}$} & \multicolumn{2}{|c|}{ Control } & \multicolumn{3}{|c|}{$4 \%$ DDT } & \multirow{2}{*}{$\begin{array}{c}\text { Corrected } \\
\text { Mortality Rate } \\
\text { (CMR) for district } \\
(\%)\end{array}$} & \multirow{2}{*}{ Result $^{1}$} \\
\hline & $\begin{array}{l}\text { Number of } \\
\text { sand flies } \\
\text { exposed }\end{array}$ & $\begin{array}{l}\text { Percent } \\
\text { mortality }\end{array}$ & $\begin{array}{l}\text { Number of } \\
\text { sand flies } \\
\text { exposed }\end{array}$ & $\begin{array}{c}\text { Percentage } \\
\text { Mortality Range } \\
\text { (PMR) }\end{array}$ & $\begin{array}{l}\text { Average } \\
\text { Mortality Rate } \\
\text { (AMR) } \\
\text { (\%) }\end{array}$ & & \\
\hline $\begin{array}{c}\text { Vaishali } \\
\text { (Daulatpur Chandi) }\end{array}$ & 20 & 0 & 70 & $41.00-52.73$ & 44.83 & 44.83 & $\mathrm{R}$ \\
\hline $\begin{array}{l}\text { Muzaffarpur } \\
\text { (Bocha) }\end{array}$ & 30 & 0 & 70 & $49.00-60.00$ & 50.00 & 50.00 & $\mathrm{R}$ \\
\hline $\begin{array}{l}\text { Samastipur } \\
\text { (Patori) }\end{array}$ & 20 & 10 & 55 & $50.00-63.65$ & 53.11 & 47.9 & $\mathrm{R}$ \\
\hline $\begin{array}{l}\text { Saran } \\
(\text { Ekma })\end{array}$ & 18 & 5.6 & 40 & $53.33-54.99$ & 54.16 & 51.44 & $\mathrm{R}$ \\
\hline $\begin{array}{l}\text { Saharsa } \\
\text { (Maheshi) }\end{array}$ & 15 & 0 & 60 & $80.00-93.33$ & 91.66 & 91.66 & $\mathrm{~T}$ \\
\hline $\begin{array}{l}\text { Gopalganj } \\
\text { (Barauli) }\end{array}$ & 17 & 6.3 & 45 & $49.99-53.56$ & 51.77 & 48.52 & $\mathrm{R}$ \\
\hline $\begin{array}{l}\text { Begusarai } \\
\text { (Baliya) }\end{array}$ & 15 & 0 & 48 & $46.42-57.14$ & 51.78 & 51.78 & $\mathrm{R}$ \\
\hline
\end{tabular}

${ }^{1} \mathrm{R}$ : Resistant, T: Tolerant

Table 1: Result of Susceptibility test for $P$. argentipes against 4\% DDT illustrating percentage mortality range, AMR and CMR for the districts of Bihar. 
Citation: Rama A, Kumar V, Kesari S, Singh VP, Das P (2015) Monitoring Susceptibility Status of Phlebotomus argentipes (Diptera: Psychodidae) at Bihar (India) for the Procurement of Homozygous DDT Resistant Colony. J Trop Dis 3: 170. doi:10.4172/2329891X.1000170

after a week of confinement, all dead insects were carefully removed from the oviposition surface with the help of needle, without disturbing eggs. Eggs were morphologically identified and counted under stereoscopic microscope (Carl Zeiss Stereoscopy Microscope, Austria; Model 426126) to avoid potential contamination with larvae of foreign insects, mites. The eggs were reared to the adult parent generation in accordance with earlier described protocol for rearing sand flies in controlled conditions [21-24]. The emerging neonates were then fed with anti-fungal larval food comprising ground rabbit faeces mixed with sand in 2:1 ratio [23]. The developing stages i.e., larvae and pupae were taken extra care in order to avoid mortality due to desiccation and food shortage. The newly emerged adult sand flies of first filial generation (i.e., F1 generation) in each Hilton pots (oviposition pots confined with single female sand fly and a male sand fly) were released into the separate cage for identifying susceptibility status after exposing them to insecticide.

\section{Resistance selection via DDT exposure}

The newly emerged female and male sand flies of parent generation from each Hilton pots were randomly selected and were probe to susceptibility analysis for understanding insecticide resistance frequency for sand flies emerged out from each oviposition pots. Approximately, 10-15 sand flies from each oviposition pots were exposed to $0.4 \%$ DDT impregnated papers for 1 hour, following 24 hours recovery from insecticide effect to classify the resistance status of tested sand flies as illustrated in Figure 2. Based upon the insecticidal susceptibility test, selection of those oviposition pots only containing $100 \%$ resistant sand flies, that had tolerated all pressures of insecticide during exposure as well as recovery session had served best for our requirement, and were regarded as 'pure DDT resistant group'. Rest of the pots exhibiting either complete or partial susceptibility towards DDT were categorised under 'susceptible' and 'mixed' group respectively. The remaining sand flies of each tested pots of 'pure DDT Resistant' group were pooled together separately into the barraud cage labelled as 'Parent generation of $0.4 \%$ DDT Resistant $P$. argentipes' for the forthcoming generations of resistant strain respectively. About 10-15 Female along with male sand flies were confined in the oviposition pots after providing bloodmeal similarly as described in previous section, for mass rearing and continuation of its next generation. The adults emerged out from the sand flies of parent generation were treated as first filial generation (i.e., F1 generation). The whole process i.e., rearing and culturing of eggs to adults and selection for resistance to $4 \%$ DDT were repeated in the same manner. Insecticide susceptibility test was carried out with 10-15 sand flies emerged out in each subsequent generations, for obtaining MFR and DRR for each generations that were calculated by using undernoted formulae.

Mortality Frequency Rate $($ MFR $)=$ Observed mortality after 24 hours of DDT exposure X 100

No. of alive sand flies after 1

hour knockdown

\section{DDT Resistant Rate (DRR)=100 - Mortality Frequency Rate (MFR)}

The calculated MFR as well as resistant rate for each generation of resistant $P$. argentipes were recorded and comparatively evaluated to obtain the insecticide resistance trend in generation of $4 \%$ DDT resistant colony of $P$. argentipes (Table 2). Till date, we have successfully colonised $7^{\text {th }}$ generations of $0.4 \%$ DDT resistant strain of $P$. argentipes following the same procedure as described in previous sub sections.

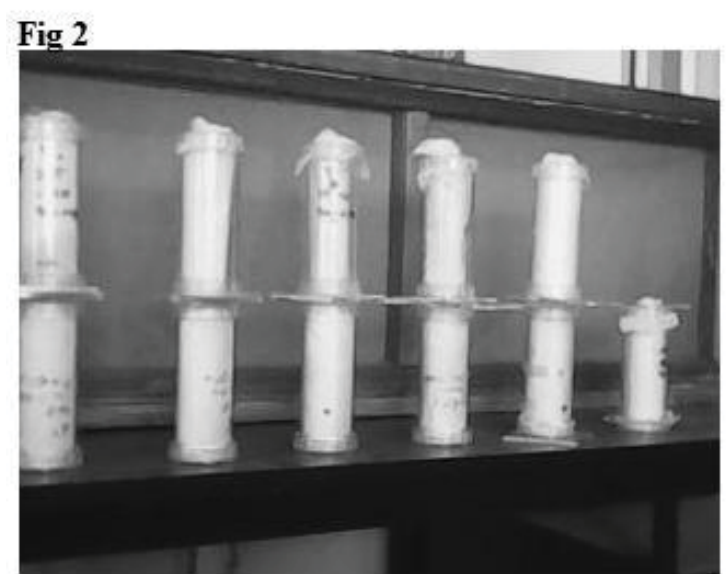

Figure 2: Experimental set-up for exposure of $\mathrm{P}$. argentipes to the DDT during WHO susceptibility test.

The animals used in the present experiment for sand fly feeding were obtained from the Animal House of Rajendra Memorial Research Institute of Medical Sciences (ICMR), Agamkuan, Patna (Bihar). After feeding, the rabbits were returned back to the animal house where they were separately kept in animal cages ( $12 \mathrm{sq} \mathrm{ft}$ with grids of 2.5 inchs) and supplemented with food and water according to the diet chart of animal house of research institute. For present study "Principles of laboratory animal care" (NIH publication No. 85-23, revised 1985) were followed for conducting research experiments involving animal. Protocols led by animal ethics committee of Indian Council of Medical Research (ICMR), Government of India, were also followed for conducting the present research work involving experiments using animal subject. All experiments had been conducted under the guidance of the Institutional ethical committee of RMRIMS (ICMR), Patna.

\section{Results}

\section{Site selection and susceptibility status of each selected study site}

In a way of site selection programme, conducted during the peak months of sand fly availability i.e., March-June and August to November in year 2011-12 and 2012-13, overall 523 engorged sand flies were collected and tested for observing current DDT susceptibility status for $P$. argentipes of shortlisted districts of Bihar viz., Vaishali, Muzaffarpur, Samastipur, Saran, Saharsa, Gopalganj and Begusarai. The results of susceptibility test for $P$. argentipes against $0.4 \%$ DDT, focusing on to the Percent Mortality Range (PMR), Average Mortality Rate (AMR) and Corrected Mortality Rate (CMR) for each districts of Bihar were obtained and illustrated in the Table 1. The lowest PMR (41.00-52.73) as well as lowest CMR (44.83\%) for Vaishali district indicated the presence of sand flies that are highly resistant towards DDT because insecticidal susceptibility and resistant are inversely proportional to each other. Along with that, highest PMR (80.0093.33) and CMR (91.66\%) observed for Saharsa district, indicated the presence of tolerant/ susceptible sand flies. The comparative result of DDT susceptibility status for $P$. argentipes caught from the shortlisted districts of Bihar individually during the year 2011-12 and 2012-13 are graphically illustrated in Figure 3 . From the results, we observe tremendous increase in average CMR that were recorded as $85 \%$, 
Citation: Rama A, Kumar V, Kesari S, Singh VP, Das P (2015) Monitoring Susceptibility Status of Phlebotomus argentipes (Diptera: Psychodidae) at Bihar (India) for the Procurement of Homozygous DDT Resistant Colony. J Trop Dis 3: 170. doi:10.4172/2329891X.1000170

Page 5 of 7

\begin{tabular}{|c|c|c|c|c|c|c|c|c|}
\hline Generations & $\begin{array}{c}\text { No. of sand flies } \\
\text { exposed }\end{array}$ & $\begin{array}{c}1 \text { hour } \\
\text { Knock Down }\end{array}$ & $\begin{array}{c}\text { Knock Down } \\
(\%)\end{array}$ & Alive & $\begin{array}{l}24 \text { hours } \\
\text { Mortality }\end{array}$ & $\begin{array}{c}\text { Mortality } \\
\text { Frequency Rate } \\
\text { (MFR) (\%) }\end{array}$ & Alive & $\begin{array}{l}\text { DDT Resistant } \\
\text { Rate (DRR) (\%) }\end{array}$ \\
\hline F1 & 15 & 3 & 20 & 12 & 4 & 33.3 & 8 & 66.66 \\
\hline $\mathrm{F} 2$ & 14 & 0 & 0 & 14 & 8 & 57.1 & 6 & 42.85 \\
\hline F3 & 10 & 0 & 0 & 10 & 4 & 40 & 6 & 60 \\
\hline $\mathrm{F} 4$ & 12 & 4 & 33.3 & 11 & 0 & 0 & 11 & 100 \\
\hline F5 & 10 & 4 & 40 & 6 & 2 & 33.3 & 4 & 66.66 \\
\hline F6 & 15 & 0 & 0 & 15 & 4 & 26.6 & 11 & 73.33 \\
\hline $\mathrm{F} 7$ & 15 & 2 & 13.3 & 13 & 5 & 38.4 & 8 & 61.53 \\
\hline
\end{tabular}

Table 2: Result of comparative observations of mortality frequencies and DRR for sand flies emerged out in subsequent generations of resistant colony of $P$. argentipes.

Year 2011-12

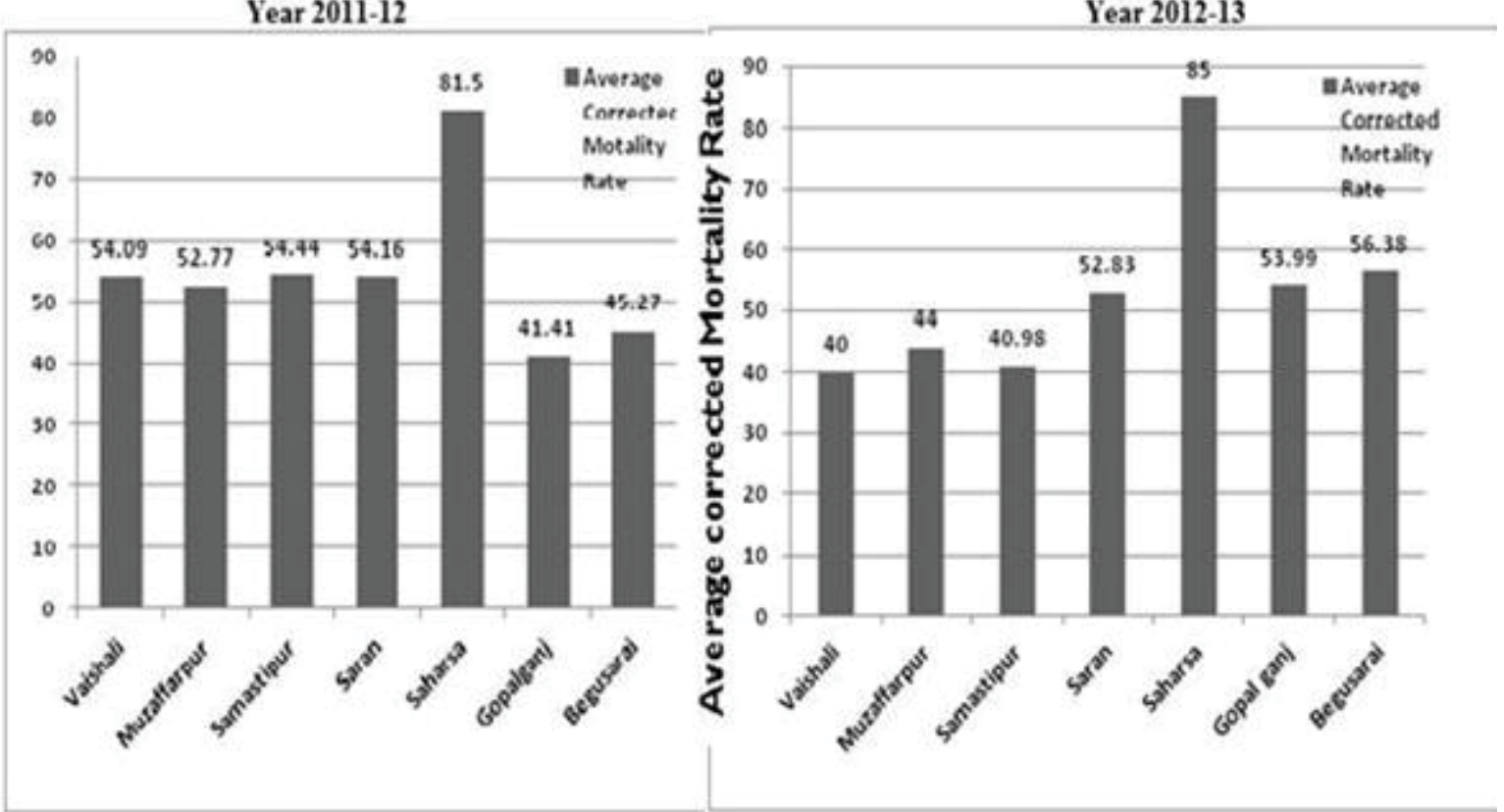

Figure 3: Graphical representation of comparison based result demonstrating average CMR for P. argentipes caught from the districts of Bihar during the year 2011-12 and 2012-13.

53.99\%, and 56.38\% for district Saharsa, Gopalganj and Begusarai respectively during the year 2012-13 as compared to those observed (i.e., $81.5 \%, 41.41 \%, 45.27 \%)$ during year 2011-12. Results establish that native sand flies of these regions are very much sensitive towards the DDT, and remained unaffected from the insecticidal resistance. As insecticidal susceptibility and resistant are inversely proportional to each other, from the same result, we also observe an abrupt decline in average CMR (i.e., $40.00 \%, 44.00 \%, 40.98 \%$ and $52.83 \%$ ) for Vaishali, Muzaffarpur, Samastipur and Saran district respectively during the year $2012-13$ as compared to those (i.e., $54.09 \%, 52.77 \%, 54.44 \%$ and $54.16 \%$ ) in previous year 2011-12. The results specifuy that the sand flies of these regions became resistant towards the DDT. Based on the obtained results, Vaishali district was crowned as 'perfect site for resistant sand fly collection' as DDT resistance was recorded to be the highest as compared to the rest of the districts.

\section{MFR and DRR for sand flies of $4 \%$ DDT resistant colony}

Out of 20 oviposition pots containing adult sand flies of parent generation, that were probed for susceptibility analysis, 12 pots were confirmed as 'pure DDT resistant group' containing sand flies that had tolerated the DDT pressure; while 2 pots were grouped under 'susceptible group' that couldn't tolerated DDT exposure and died (55.55\%) within an hour of insecticidal exposure as well as in 24 hours $(42.59 \%)$ of recovery period from insecticidal exposure. The remaining 6 pots were categorised under 'mixed group' containing mixed type of sand flies exhibiting $42.62 \%$ mortality. For studying resistant profile of adult $P$. argentipes emerged out in every subsequent generations of newly established DDT resistant colony, we exclusively focussed on observing Mortality Frequency Rate (MFR) and DDT Resistant Rate (DRR) rather than the CMR for P. argentipes emerged out in each subsequent generation due to insufficient and uncertain availability of sand flies for control sets during the DDT susceptibility test. Result comparing the MFR and DRR of sand flies emerged out in the subsequent generations of confinement of parent generation of $P$. argentipes are illustrated in the following Table 2. Results of MFR and DRR for $P$. argentipes emerged out in subsequent generation, revealed fluctuations in observed data. Comparing the susceptibility result of $P$. argentipes emerged out at each generations, it was observed that sand 
Citation: Rama A, Kumar V, Kesari S, Singh VP, Das P (2015) Monitoring Susceptibility Status of Phlebotomus argentipes (Diptera: Psychodidae) at Bihar (India) for the Procurement of Homozygous DDT Resistant Colony. J Trop Dis 3: 170. doi:10.4172/2329891X.1000170

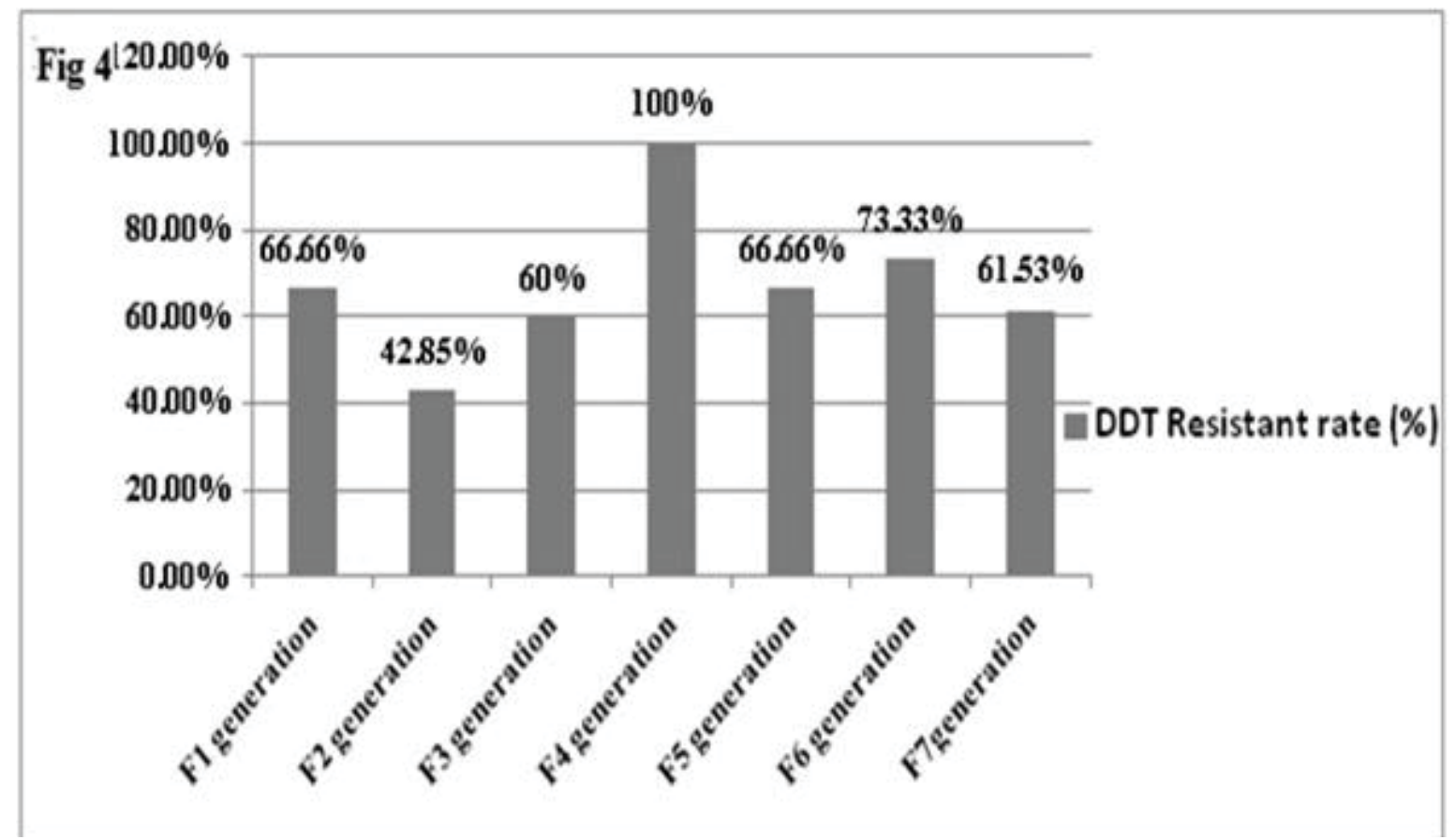

Figure 4: Graphical representation of comparison based result demonstrating mortality frequencies and DRR for P. argentipes emerged out in subsequent generations of resistant colony.

flies of F2 generation possess lowest resistance (42.85\%) indicating highest susceptibility, as insecticidal susceptibility and resistance are indirectly proportional to each other. Also, sand flies of F4 generation had attained peak resistance (100\%) indicating absolute resistant towards DDT that gradually lowered till F7 generation. The data are graphically illustrated in Figure 4. Significant fluctuation within DRR (with $67.29 \pm 17.28$; 95\% C.I=54.49-80.09) was observed throughout the $7^{\text {th }}$ generation establishing intrusion of susceptibility factor in homozygous resistant colony of $P$. argentipes after achieving absolute resistant in F4 generation of $P$. argentipes. Though invaded with insecticide susceptibility, resistance dominate the colony. So far, colony has reached its $7^{\text {th }}$ generation and culturing well in the laboratory.

\section{Discussion}

Insecticides indeed play a vital role in controlling the vector nuisance for reducing the disease burden under Integrated Disease Management (IDM). Previous reports confirms the reductions in VL cases, during 1960-70, as a collateral benefit of DDT spraying for malaria control programmes under National Malaria Control Programme and National Malaria Eradication Program launched in year 1953 and 1958 respectively [25], and hence the populations of $P$. argentipes were also effectively suppressed due to higher level of susceptibility to DDT [26]. Before 1979, P. argentipes of Bihar state was considered to be highly susceptible to DDT in WHO susceptibility test [7], but brisk, continuous and injudicious use of insecticide in this region for long had evoked the problem of DDT resistance in $P$. argentipes population of Bihar $[8,9,15]$. This definitely obstructed the insecticide based strategies applied for controlling vector population. In this context, well established, DDT resistant colony of Phlebotomus argentipes (Diptera: Psychodidae) is supposed to be of great value to reveal the physiological consequences of insecticide resistance on this species. This could also helped in understanding the mechanistic reason behind the arousal of insecticide resistance among the population followed by experimenting new strategies that might encounter physiological resistance among these species. Hence, to fulfill the requirement, the DDT resistant colony of $P$. argentipes was initiated during 2014, after studying susceptibility profile for districts of Bihar in from year 2011-13 and collecting sand flies from the area with high DDT resistance level. The Susceptibility test was conducted at the seven districts viz., Vaishali, Muzaffarpur, Samastipur, Saran, Saharsa, Gopalganj and Begusarai of Bihar state in order to estimate the current DDT resistant profile for $P$. argentipes in Bihar. The districts were shortlisted as they are geographically positioned at the northern side of Ganges course in Bihar and are highly endemic for VL [11-14]. Here, despite of adopting every technique for controlling the menace caused by vector population, resurgence of sand flies had been continuously reported indicating arousal of resistance among the sand flies $[15,16]$. Among these, sand flies of district Saharsa (25 $53^{\prime} 0$ " N, $86^{\circ} 36^{\prime} 0^{\prime \prime}$ E) with highest percentage mortality range (80.00-93.33) as well as highest CMR (91.66\%) signifies the lowest resistance. Whereas, Daulatpur Chandi village of Vaishali district $\left(25.6833^{\circ} \mathrm{N}, 85.2167^{\circ} \mathrm{E}\right)$ with lowest PMR (41.00-52.73) and lowest CMR (44.83\%) indicated the existence of sand flies that are highly resistant towards DDT, and wellsuited for establishment of DDT resistant colony after collection of sand flies from this district. Final outcome of present DDT susceptibility test conducted at the districts of Bihar supported the previous reports of susceptibility status of $P$. argentipes in Bihar, India [12,13,15]. Sand flies were captured from Vaishali district and confined in each oviposition pots (comprising single fed female and a male insect) and reared till adult emergence [21-24]. All the adults emerged out from the the single female sand fly were supposed to bear similar identity in context to DDT resistant, as their parent exhibited and evenly pass on to its subsequent generations [27]. The progenies of wild captured sand flies 
Citation: Rama A, Kumar V, Kesari S, Singh VP, Das P (2015) Monitoring Susceptibility Status of Phlebotomus argentipes (Diptera: Psychodidae) at Bihar (India) for the Procurement of Homozygous DDT Resistant Colony. J Trop Dis 3: 170. doi:10.4172/2329891X.1000170

that already exhibited a high level of resistance to DDT indicated very low proportion of susceptible individual living in natural condition. The inherited DDT resistant character exhibited by the progenies of highly resistant parents was estimated by quantifying the level of MFR and DRR through insecticide susceptibility test, for $P$. argentipes at each subsequent generations of colony. The peak of DRR gradually increased after F2 generation achieving absolute resistance towards DDT in colony comprising $100 \%$ resistant sand flies in F4 generation. The result exhibited the fluctuations in peak of DRR after F4 generation establishing intrusion of susceptibility character in the homozygous resistant colony of $P$. argentipes. However, the estimation of DDT resistant level on molecular and biochemical ground is awaited, till now, we can say that though infected with susceptibility characteristics due to various factors viz., environmental factors, physiological stresses, etc., resistant factor dominates the colony of $P$. argentipes [28]. So far, colony has reached its $7^{\text {th }}$ generation and culturing well in the laboratory. The selection process of DDT resistant sand flies in each generation should be continued in same manner to achieve stable resistance level [27]. The stable DDT resistant colony would facilitate studying cross- resistance of VL vector towards various insecticides in order to explore new control strategies for vector control under Integrated Vector Management (IVM).

\section{Acknowledgement}

Present work is a part of study under PhD programme [Registration No. 3700/ $\mathrm{PhD}$. (Sc.) proceed 2014] entitling "Study of behavioral responses in the offspring emerged out from single parent insect of 4\% DDT resistant strain Phlebotomus argentipes (Diptera: Psychodidae) the vector of kala-azar (Visceral Leishmaniasis) in Indian subcontinent" progressing under the supervision of Calcutta University and financially sponsored by University Grant Commission, India with vide gran number [RGNF 2012-13-ST-BIH-20305] and RMRIMS (ICMR), Agamkuan, Patna-07, Bihar, with study ID No. [INT - 83 -VBC] "Study on the semiochemical mediated response in the oviposition behaviour of $P$. argentipes". The authors cordially express their gratitude towards NK Sinha, SA Khan, AK Mandal, BB Prasad and all members of Vector Biology and Control Division for their excellent technical support and help during experiment and manuscript documentation session. Thanks are also due to the Scientific Advisory Committee (SAC) of Rajendra Memorial Research Institute of Medical Sciences (ICMR), Institutional Ethical Committee as well as to the Animal Ethics Committee for their kind approval to conduct the research study.

\section{Conflict of Interests}

None to declare

\section{References}

1. Metcalf RL (1955) Physiological basis for insect resistance to insecticides. Physiol Rev 35: 197-232.

2. Ware GW, Whitacre DM (2004) An Introduction to Insecticides (4th edition), (6th edn), Meister Pro Information Resources, A division of Meister Media Worldwide, Willoughby, Ohio.

3. Sacca G (1947) "Sull'esistenza di Mosche Domestiche Resitenti al DDT." Riv di Parassitol 8:127.

4. Insecticide Resistance Action Committee (IRAC) (2011) 2nd edition.

5. Busvine JR (1956) The significance of insecticide-resistant strains; with special reference to pests of medical importance. Bull World Health Organ 15: 389 401.

6. Kaul SM, Wattal BL, Bhatnagar VN, Mathur KK (1978) Preliminary observations on the susceptibility status of Phlebotomnus argentipes and P. papatasi to DDT in two districts of north Bihar (India). J Comm Dis 10: 208-211.

7. Joshi GC, Kaul SM, Wattal BL (1979) Susceptibility of sand flies to organochlorine insecticides in Bihar (India)-further reports. J Comm Dis 11: 209-213.

8. Mukhopadhyay AK, Chakravarty AK, Kureel VR, Shivraj (1987) Resurgence of Phlebotomus argentipes \& Ph. papatasi in parts of Bihar (India) after DDT spraying. Indian J Med Res 85: 158-160.
9. Mukhopadhyay AK, Sexena NBLK, Narasimhan MVVL (1992). Susceptibility status of Phlebotomus argentipes to DDT in some Kala-azar endemic districts of Bihar, India. Geneva.

10. El-Sayed S, Hemingway J, Lane RP (1989) Susceptibility baseline for DDT metabolism and related enzyme systems in the sand fly Phlebotomus papatas (Scopoli) (Diptera: Psychodidae). Bull Ent Res. 79: 679-684.

11. Dhiman RC, Sen AB (1991) Epidemiology of kala-azar in rural Bihar (India) using village as a component unit of study. Indian J Med Res 93: 155-160.

12. Dhiman RC, Raghavendra K, Kumar V, Kesari S, Kishore K (2003) Susceptibility status of Phlebotomus argentipes to insecticides in districts Vaishaii and Patna (Bihar). J Commun Dis 35: 49-51.

13. Kishore K, Kumar V, Kesari S, Bhattacharya SK, Das P (2004) Susceptibility of Phlebotomus argentipes against DDT in endemic Districts of North Bihar, India. $\mathrm{J}$ Commun Dis 36: 41-44.

14. Kumar V, Kesari SK, Sinha NK, Palit A, Ranjan A, et al. (1995). Field trail of an ecological approach for the conrol of Phlebotomus argentipes using mud \& lime plaster. Indian J Med Res 101: 154-156.

15. Singh R, Das RK, Sharma SK (2001) Resistance of sandflies to DDT in Kalaazar endemic districts of Bihar, India. Bull World Health Organ 79: 793.

16. Kumar V, Kesari S, Kumar AJ, Dinesh DS, Ranjan A, et al. (2009). Vector density and the control of kala-azar in Bihar, India. Mem Inst Oswaldo Cruz 104: 1019-1022.

17. World Health Organization (1981) Instructions for determining the susceptibility or resistance of adults Blackflies, sandflies and biting midges to insecticides. Geneva.

18. World Health Organization (1998) Test procedures for insecticide resistance monitoring in malaria vectors, bio-efficacy and persistence of insecticides on treated surfaces. Geneva.

19. Dinesh DS, Das ML, Picado A, Roy L, Rijal S, et al. (2010) Insecticide susceptibility of Phlebotomus argentipes in visceral leishmaniasis endemic districts in India and Nepal. PLoS Negl Trop Dis 4: e859.

20. Lewis DJ (1978) The phlebotomine sand flies (Diptera: Psychodidae) of the Oriental Region. Bull Br Mus Nat Hist 37.

21. Kumar V, Kesari S, Kumari K, Kumari BK, Venugopalan R, et al. (2011) Comparison of In Vivo Host Animals as Blood-Feeding Source for Laboratory Rearing of the Sandfly Vector Phlebotomus argentipes (Diptera: Psychodidae). Ann Entomol Soc Am 104: 429-433.

22. Kumar V, Rama A, Kesari S, Bhunia GS, Dinesh DS (2013) Oviposition behaviour of Phlebotomus argentipes - A laboratory-based study. Mem Inst Oswaldo Cruz 108: 1065-1067.

23. Rama A, Kesari S, Dinesh DS, Seema K, Das P, et al. (2014) Vertebrate excreta based semiochemical influencing oviposition and neonates' survival in Phlebotomus argentipes- Visceral Leishmaniasis vector in Indian subcontinent. 2: $172-178$.

24. Modi GB, Tesh RB (1983) A simple technique for mass rearing Lutzomyia longipalpis and Phlebotomus papatasi (Diptera: Psychodidae) in the laboratory J Med Entomol 20: 568-569.

25. Sanyal RK, Banerjee DP, Ghosh TK, Ghosh JN, Misra BS, et al. (1979). A Longitudinal Review of Kala azar in Bihar. J Comm Dis 11: 149-169.

26. Kishore K, Kumar V, Kesari S, Dinesh DS, Kumar AJ, et al. (2006) Vector control in leishmaniasis. Indian J Med Res 123: 467-472.

27. Wang DQ, Xia ZG, Zhou SS, Zhou XN, Wang RB, et al. (2013). A potential threat to malaria elimination: extensive deltamethrin and DDT resistance to Anopheles sinensis from the malaria-endemic areas in China. Malar J 12: 164

28. Zhu G, Zhou H, Li J, Tang J, et al. (2014) The colonization of pyrethroid resistant strain from wild Anopheles sinensis, the major Asian malaria vector. Parasit Vectors 7: 582 